\title{
Adolescentes: conhecimentos sobre sexualidade antes e após a participação em oficinas de prevenção
}

\author{
Adolescents: knowledge about sexuality \\ before and after participating in prevention workshops
}

Elisana Ágatha I akmiu Camargo ${ }^{1}$

Rosângela A parecida Pimenta Ferrari ${ }^{2}$

1 Departamento de Enfermagem, Centro de Ciências da Saúde,

Universidade Estadual de Londrina. RuaFrancisco

Marcelino da Silva 250 Jardim Itatiaia-2. 86047-160 Londrina PR. enfermeiradis@yahoo.com.br. 2 Departamento de Enfermagem (Saúdeda Criança edo Adolescente) Centro deCiências da Saúde, Universidade Estadual deLondrina.
Abstract Teenagers go through biological/psychosocial changes including experiencing his/her sexuality. Adolescent sexuality is often shown in unsafe sexual practices; lack of information, taboos or even the fear of accepting one's sexuality can turn it into a problem. Thisstudy aims at analyzing the knowledge of adolescents on sexuality, contraceptive methods, pregnancy, STD/AIDS before and after prevention workshops. 117 8th grade students of a public school in Londrina, Paraná, ages 14 to 16 , comprised the sample. A pre and post-test questionnaire was used and data analysis was based on the chi-square and Fisher's exact tests. Boys began their sexual activity earlier than girls. In the pre test, $28.2 \%$ of theadolescents were informed about the girl's fertile period ; after the workshops, this ratesurpassed $55.8 \%$. In the pre-test, AIDS was the most frequently mentioned STD; in the post-test other STDs were brought up $(41.1 \%)$. The most well-known contraceptive methods were condoms and the pill. No statistically significant difference was found between the answers about risk behavior in relation to STD/AIDS transmission. Thus, it is necessary to reflect about and discuss ways of approaching the issue in schools in order to provide the adolescents with the knowledge they need to live their sexuality more safely.

Key words Adolescence, Sexuality, Prevention workshops
Resumo Na adolescência, a vivência da sexualidade torna-se mais evidente. M uitas vezes, manifestase através de práticas sexuais inseguras, podendo se tornar um problema devido à falta de informação, tabus ou mesmo pelo medo de assumi-la. 0 objetivo da pesquisa foi analisar o conhecimento dos adolescentes sobre sexualidade, métodos contraceptivos, gravidez, DST eaids, anteseapósoficinas deprevenção. Participaram 117 adolescentes da 8a série de uma escola estadual de Londrina, Paraná. Foi utilizado um questionário (prée pós-teste) para identificar a diferença do conhecimento dos adolescentes. Para a análise dos dados, usaram-se ostestes quiquadrado e exato de Fischer. A faixa etária concentrouse entre 14 e 16 anos. Os meninos iniciaram mais cedo suasatividades sexuais. A penas $28,2 \%$ dosadolescentes no pré-teste sabiam do período fértil da menina; após as oficinas de prevenção, o conhecimento superou $55,8 \%$. A aids foi a DST mais citada no pré teste; no pós-teste, houve referência a outras doenças $(41,1 \%)$. Os métodos contraceptivos mais conhecidos são o preservativo e a pílula. N ão houve relevância estatística entre as respostas sobre atitudes de risco para transmissão de DST/aids. Concluise que há necessidade de trabalho sistemático, a mé dio elongo prazo, sobresexualidadena escola para os adolescentes.

Palavras-chave Adolescência, Sexualidade, O ficinas de prevenção 
Introdução

A adolescência é um período de transição para a maturidade, com o desenvolvimento físico sempre precedendo o psicológico. É por assi $m$ dizer, 0 elo entre a infância e a idade adulta ${ }^{1}$. Segundo a Organização M undial da Saúde, a adolescência é a idade correspondente dos 10 aos 19 anos, sendo a pré-adolescência dos 10 aos 14 anos e a adolescência, propriamente dita, dos 15 aos 19 anos².

N esta fase da vida, ocorre aceleração e desaceleração do crescimento físico, mudança da composição corporal, eclosão hormonal, envolvendo hormônios sexuais e evolução da maturidade sexual, acompanhada pelo desenvolvimento de caracteres sexuais secundários masculinos e femininos. Paralelamente às mudanças corporais, ocorrem as psicoemocionais, como a busca da identidade, a tendência grupal, o desenvolvimento do pensamento conceitual, a vivência singular e a evolução da sexualidade?

Astransformações dessa fase da vida fazem com que 0 adolescente viva intensamente sua sexualidade, manifestando-a muitas vezes através de práticas sexuais desprotegidas, podendo se tornar um problema devido à falta de informação, de comunicação entre os familiares, tabus ou mesmo pelo fato de ter medo de assumi-la. A evolução de suas sensações, comportamentos e decisões sexuais será influenciada pelas interações que desenvolve com outros jovens do seu vínculo familiar e social ${ }^{4}$.

Segundo Calazans, a concepção a respeito da sexualidade ainda éum desafio a ser instituído em nossa sociedade, pois ela ainda vê o tema apenas ligado a fatores biológicos, excluindo-o de influências históricas, culturais e sociais $5^{5}$.

A pesar do avanço científico no que diz respeito ao estudo sobre sexualidade humana, este tema ainda é impregnado de mitos, preconceitos e contradições, a ponto de muitas pessoas continuarem afirmando que só deve ser discutido entre adultos, o queé prejudicial para o desenvolvimento ecomportamento sexual saudável dos adolescentes ${ }^{6}$.

A identidade sexual e social de cada um de nós é construída, segundo a família (uma miniatura da sociedade), através da visão de mundo evalores que herdamos dos nossos pais. Refere ainda que é na escola que o jovem entra em contato com outros valores e significados e, ao confrontar ao herdado, elabora sua própria conduta, ou seja, caberia à escola oferecer aos jovens uma realidade diferente da família?.

A escola significa um lugar importante para se trabal har conhecimentos, habilidades e mudanças de comportamento, pois é local em que 0 adolescente permanece o maior tempo do seu dia.

Portanto, torna-se um local propício e adequado para o desenvolvimento de ações educativas, atuando nas diferentes áreas dos saberes humanos.

Em contrapartida, Lins et al. referem que há uma lacuna de informações pela falta da educação sexual nas principais instituições em que os adolescentes convivem; entreelas, destacam-sea escola e a família. A conseqüência disso são os sentimentos de culpa e de medo que atingem essa faixa etária, fazendo com que estes passem a buscar informações em fontes pouco seguras ou incapazes de ajudá-los ${ }^{8}$.

No entanto, torna-se necessário conhecer me Ihor o que os adolescentes pensam, sua realidade, mitos e tabus com respeito a sua sexualidade para que se possa abordá-la de modo a contribuir para o seu crescimento edesenvolvimento sexual saudável ${ }^{9}$.

Neste sentido, esta pesquisa teve como objetivo analisar o conhecimento dos adolescentes sobre sexualidade, métodos contraceptivos, gravidez edoenças sexualmentetransmissíveis egênero, antes eapós a participação nas oficinas de prevenção.

\section{M etodologia}

Trata-se de uma pesquisa quantitativa utilizandose parte de um banco de dados do projeto de pesquisa Educação sexual para adolescentes: implementação e avaliação de uma experiência para enfermagem, realizado nos anos de 2001 a 2004.

A população estudada constituiu-se por 117 adolescentes, participantes das oficinas de prevenção, das três turmas da $8^{a}$ série do ensino fundamental de uma escola estadual de ensino fundamental e médio, na região sul do município, que atende cerca de 1.200 alunos nos períodos matutino, vespertino e noturno.

A seleção amostral foi construída partindo de dois pontos fundamentais: a necessidade da escola e os resultados apontados em pesquisas de âmbito nacional e regional, visto que é neste grupo etário que se dá a iniciação sexual; sendo assim, a realização de trabalhos de interven ção preventiva se faz necessária.

0 município conta com 447.065 habitantes; deste total, 83.550 (18,7\%) são adolescentes, 9,0\% na faixa etária de 10-14 anos e 9,7\% na faixa etária de 15-19 anos, não diferindo significantemente os sexos ${ }^{10}$.

Londrina possui 49 escolas estaduais e 65 escolas municipais. Na região sul, existem dez escolas municipais de ensino fundamental e seis escolas 
estaduais de ensino fundamental e médio; dentre as escolas estaduais está a instituição onde o projeto de pesquisa foi desenvolvido por dois anos consecutivos.

Para a coleta de dados, utilizou-se um questionário construído com questões de múltipla escolha para a obtenção dos dados necessários à análise do objeto de estudo, contendo dados quanto à idadee sexo dos adolescentes e questões referentes à sexualidade, métodos contraceptivos, gravidez, doenças sexualmente transmissíveis (DST) e gênero.

A coleta dos dados para a pesquisa ocorreu em três momentos: primeiro, foi aplicado o questionário (pré-teste) para identificar o conhecimento dos adolescentes; segundo, realizou-se duas oficinas de preven ção com grupos de dez a quinze participantes, limites mínimo e máximo, que se fize ram em dois encontros, totalizando oito horas. As oficinas foram realizadas utilizando-se de dinâmicas contidas no Manual do Multiplicador do $\mathrm{Mi}$ nistério da Saúde ${ }^{11}$. A primeira oficina abordou 0 tema sexualidade ( $p$ ráticas sexuais, desenvolvimento e transformação do corpo, o prazer e as relações de gênero), métodos contraceptivos, as mudanças do corpo na gravidez e as suas repercussões biopsicossociais na adolescência. A segunda oficina abordou os métodos de prevenção das DST e aids, as formas de contágio e as repercussões biopsicossociais da infecção; no terceiro e último momento, após três meses da realização das oficinas de prevenção, aplicou-se o mesmo questionário (pós-teste) com o intuito de identificar a mudança de conhecimento dos adolescentes.

Os dados coletados na pesquisa foram categorizados, digitados e analisados em um banco de dados estruturado no programa Epi-Info 3.3.212. Para a análise, foram utilizados os testes quiquadrado $\left(\chi^{2}\right)$ e exato de Fischer, com um valor de significância de $p<0,05$. Foi necessária a aplicação deste segundo teste pelo fato de haver alguns resultadosqueapresentaram freqüênciasinferioresaum.
Estes testes foram aplicados para comparar as respostas entre meninos e meninas, tanto no pré quanto no pós-teste, para saber se houve diferença de opinião entre os sexos e também para analisar se houve mudança do conhecimento após a participação nas oficinas de preven ção.

A pesquisa cumpriu as normas da Resolução no 196, de 10 de outubro de 1996, do Conselho Nacional de Saúde ${ }^{13}$. Foi aprovada pelo Comitê de Ética em Pesquisa da Universidade Estadual de Londrina, parecer CEP-005/01.

\section{Resultados}

Participaram da pesquisa 117 adolescentes (100\%); desses, a totalidade respondeu o pré teste e participou das oficinas de prevenção, mas, no dia da coleta do pós-teste, $95(81,2 \%)$ participaram e 22 $(18,8 \%)$ não estavam presentes.

A Tabela 1 aponta a faixa etária e o sexo da população de estudo. N ota-se que $41,9 \%$, no pré teste, e $43,2 \%$, no pós-teste, dos adolescentes eram do sexo masculino; já com relação às meninas, $58,1 \%$ e $56,8 \%$ correspondiam ao pré e pós-teste, respectivamente.

$\mathrm{Na}$ Tabela 2, observa-se que os resultados não diferem no prée pós-teste quanto ao conhecimento dos garotos sobre a localização do clitóris no corpo feminino. Em contrapartida, houve melhora do conhecimento das garotas de $22,1 \%$ para $53,7 \%$, respectivamente. Entretanto, 0 aprendizado tanto dos meninos quanto das meninas, após as oficinas, não atingiu os $50 \%$.

Com relação à masturbação, os adolescentes deste estudo em sua maioria afirmam ser uma forma saudável de conhecer o corpo (70,9\% no préteste e $75,8 \%$ no pós-teste).

Foi perguntado para os estudantes a respeito do início da vida sexual. Pôde-se evidenciar que houve diferenças significativas $(p<0,05)$ entreme-

Tabela 1. Distribuição dos adolescentes da 8ạ série do ensino fundamental de uma escola pública, quanto ao sexo e faixa etária. Londrina, 2005.

\begin{tabular}{|c|c|c|c|c|c|c|c|c|c|c|c|c|}
\hline \multirow{3}{*}{ Faixa etária } & \multicolumn{6}{|c|}{ Pré-teste } & \multicolumn{6}{|c|}{ Pós-teste } \\
\hline & \multicolumn{2}{|c|}{ Meninos } & \multicolumn{2}{|c|}{ Meninas } & \multicolumn{2}{|c|}{ Total } & \multicolumn{2}{|c|}{ Meninos } & \multicolumn{2}{|c|}{ Meninas } & \multicolumn{2}{|c|}{ Total } \\
\hline & $\mathrm{N}$ & $\%$ & $\mathrm{~N}$ & $\%$ & $\mathrm{~N}$ & $\%$ & $\mathrm{~N}$ & $\%$ & $\mathrm{~N}$ & $\%$ & $\mathrm{~N}$ & $\%$ \\
\hline 14-16 anos & 43 & 38,7 & 68 & 61,3 & 111 & 94,9 & 40 & 42,6 & 54 & 57,4 & 94 & 98,9 \\
\hline 17-19 anos & 2 & 4,1 & - & - & 2 & 1,7 & - & - & - & - & - & - \\
\hline Em branco & 4 & 8,2 & - & - & 4 & 3,4 & 1 & 2,4 & - & - & 1 & 1,1 \\
\hline Total & 49 & 41,9 & 68 & 58,1 & 117 & 100,0 & 41 & 43,2 & 54 & 56,8 & 95 & 100,0 \\
\hline
\end{tabular}


ninosemeninas: $24,5 \%$ dos garotos no prée $31,7 \%$ no pós-teste já tiveram relação sexual, mas entre as garotas apenas 4,4\% e 5,6\%, no pré e pós-teste, respectivamente.

Tornou-se pertinente, devido à constatação da iniciação sexual precoce, conferir o que os adolescentes sabem a respeito de métodos contraceptivos, da gravidez e das DST.

Com relação ao conhecimento dos adolescentes sobre os métodos contraceptivos, especificamente o preservativo e a pílula, tanto no pré-teste quanto no pós-teste, não houve diferença estatisticamente significativa para ambos os sexos, 53,0\% e $46,3 \%$, respectivamente.

Quanto ao conhecimento sobre o período do mês que uma garota pode engravidar, a Tabela 3 mostra as diferenças das respostas entre meninos e meninas.

Nota-se que, no préteste, $51,1 \%$ dos meninos e 27,8\% das meninas não sabem qual o período do mês que a garota pode engravidar. No pós-teste, estes números foram menores, $41,5 \%$ dos meninos e $7,5 \%$ das meninas.
Ainda pôde-se observar no préteste que o conhecimento das meninas é pequeno, pois $38,3 \%$ referem no começo ou no fim da menstruação, 0 que corrobora os dados referidos anteriormente, o menor conhecimento das adolescentes sobre seu próprio corpo.

A resposta correta seria entre uma menstruação e outra, mas apenas $22,4 \%$ dos meninos e $32,4 \%$ das meninas conheciam esta informação no pré teste; no pós-teste, houveaumento do conhecimento, subindo para $41,5 \%$ e $66,7 \%$, respectivamente.

0 percentual de respostas corretas foi crescente entre o pré e pós-teste, ou seja, após as oficinas, mais da metade dos adolescentes $(55,8 \%)$ responderam corretamente sobre o período fértil da menina. Ainda assim, estenúmero continua baixo, pois 22,2\% ainda afirmam não saber sobre 0 assunto.

Q uanto ao conhecimento sobre DST e aids, a Tabela 4 mostra que não houve diferenças estatisticamente significativa entre as respostas dos adolescentes no pré-teste; já no pós-teste, há distinção entre meninos e meninas, confirmado principalmente pelo fato de $39 \%$ dos garotos citarem ape-

Tabela 2. Distribuição dos adolescentes da 8a série do ensino fundamental de uma escola pública, quanto às respostas sobre conhecimento da localização do clitóris. Londrina, 2005.

\begin{tabular}{|c|c|c|c|c|c|c|c|c|c|c|c|c|}
\hline \multirow{3}{*}{$\begin{array}{l}\text { Conhece a } \\
\text { Iocalização do } \\
\text { clitóris }\end{array}$} & \multicolumn{6}{|c|}{ Pré-teste } & \multicolumn{6}{|c|}{ Pós-teste } \\
\hline & \multicolumn{2}{|c|}{ Meninos } & \multicolumn{2}{|c|}{ Meninas } & \multicolumn{2}{|c|}{ Total } & \multicolumn{2}{|c|}{ Meninos } & \multicolumn{2}{|c|}{ Meninas } & \multicolumn{2}{|c|}{ Total } \\
\hline & $\mathrm{N}$ & $\%$ & $\mathrm{~N}$ & $\%$ & $\mathrm{~N}$ & $\%$ & $\mathrm{~N}$ & $\%$ & N & $\%$ & $\mathrm{~N}$ & $\%$ \\
\hline Sim & 18 & 36,7 & 15 & 22,1 & 33 & 28,2 & 16 & 39,0 & 29 & 53,7 & 45 & 47,4 \\
\hline Não & 31 & 63,3 & 53 & 77,9 & 84 & 71,8 & 25 & 61,0 & 25 & 46,3 & 50 & 52,6 \\
\hline Total & 49 & 100,0 & 68 & 100,0 & 117 & 100,0 & 41 & 100,0 & 54 & 100,0 & 95 & 100,0 \\
\hline
\end{tabular}

Tabela 3. Distribuição dos adolescentes da 8a série do ensino fundamental de uma escola pública, quanto às respostas sobre o período do mês que a garota pode engravidar. Londrina, 2005.

\begin{tabular}{|c|c|c|c|c|c|c|c|c|c|c|c|c|}
\hline \multirow{3}{*}{$\begin{array}{c}\text { Período do mês que a garota } \\
\text { pode engravidar }\end{array}$} & \multicolumn{6}{|c|}{ Pré-teste } & \multicolumn{6}{|c|}{ Pós-teste } \\
\hline & \multicolumn{2}{|c|}{ Meninos } & \multicolumn{2}{|c|}{ Meninas } & \multicolumn{2}{|c|}{ Total } & \multicolumn{2}{|c|}{ Meninos } & \multicolumn{2}{|c|}{ Meninas } & \multicolumn{2}{|c|}{ Total } \\
\hline & $\mathrm{N}$ & $\%$ & $\mathrm{~N}$ & $\%$ & $\mathrm{~N}$ & $\%$ & $\mathrm{~N}$ & $\%$ & $\mathrm{~N}$ & $\%$ & $\mathrm{~N}$ & $\%$ \\
\hline Começo da menstruação & 3 & 6,1 & 11 & 16,2 & 14 & 12,0 & 1 & 2,4 & 4 & 7,4 & 5 & 5,3 \\
\hline Durante a menstruação & 4 & 8,2 & 1 & 1,5 & 5 & 4,3 & 2 & 4,9 & 5 & 9,3 & 7 & 7,4 \\
\hline Entre uma e outra menstruação & 11 & 22,4 & 22 & 32,4 & 33 & 28,2 & 17 & 41,5 & 36 & 66,7 & 53 & 55,8 \\
\hline No fim da menstruação & 6 & 12,2 & 15 & 22,1 & 21 & 17,9 & 4 & 9,8 & 5 & 9,3 & 9 & 9,5 \\
\hline Não sabe & 25 & 51,1 & 19 & 27,8 & 44 & 37,6 & 17 & 41,5 & 4 & 7,5 & 21 & 22,2 \\
\hline \multirow[t]{3}{*}{ Total } & 49 & 100,0 & 68 & 100,0 & 117 & 100,0 & 41 & 100,0 & 54 & 100,0 & 95 & 100,0 \\
\hline & \multicolumn{2}{|c|}{$* p=0,018$} & & & & & \multirow{2}{*}{\multicolumn{2}{|c|}{$* * p=0,002$}} & & & & \\
\hline & & & & & & & & & & & & \\
\hline
\end{tabular}


nas a aids como uma DST e as garotas referirem outras doenças como sífilis, herpes genital, hepatite e HPV - Papiloma Vírus Humano (53,7\%).

Pode-se observar que houve mudanças significativas entre as respostas dos adolescentes em ambos os momentos.

No pré-teste, a DST mais conhecida foi a aids $(43,6 \%)$; já no pós-teste, foram citadas diferentes doenças $(41,1 \%)$, evidenciando que os estudantes, após as ofi cinas, tiveram a oportunidade de entrar em contato com outras informações sobre a diversidade de doenças transmitidas na relação sexual, além da aids.

Quanto às questões referentes aos meios de transmissão das DST pela via sexual (anal, oral e vaginal) sem o uso do preservativo, pela via transfusão sanguínea e pelo compartilhamento de dro- gas injetáveise também por outros meios de transmissão veiculados como popularmente verdadeiras (compartilhar toalha e banheiro, abraçar e beijar), não houve diferença estatisticamente significativa entre as respostas dos meninos e das meninas em ambos os momentos das oficinas, ou seja, não foi observada mudança de conhecimento após a participação nas oficinas de prevenção.

Notou-se que a maioria dos adolescentes não conseguiu identificar todas as formas de transmissão (78,6\% no pré-teste e $79,5 \%$ no pós-teste). N o entanto, apenas 3,1\% no pós-teste assinalaram alguma alternativa errada.

Quando se fala de prazer sexual, preocupa a possibilidade de os adolescentes possuírem opiniões errôneas. A Tabela 5 mostra que não houve diferenças significantes entre as respostas dos me-

Tabela 4. Distribuição dos adolescentes da 8ạ série do ensino fundamental de uma escola pública, quanto ao conhecimento das DST. Londrina, 2005.

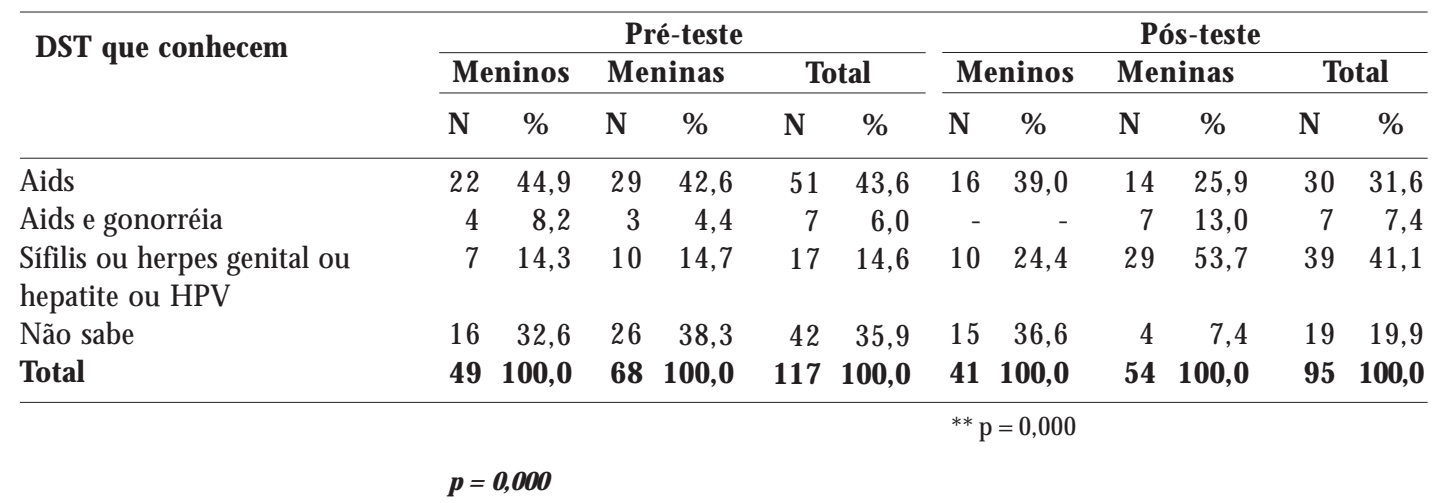

Tabela 5. Distribuição dos adolescentes da 8ạ série do ensino fundamental de uma escola pública, a respeito do que pensam sobre o prazer sexual. Londrina 2005.

\begin{tabular}{|c|c|c|c|c|c|c|c|c|c|c|c|c|}
\hline \multirow{3}{*}{$\begin{array}{c}\text { O que os adolescentes } \\
\text { pensam sobre prazer sexual }\end{array}$} & \multicolumn{6}{|c|}{ Pré-teste } & \multicolumn{6}{|c|}{ Pós-teste } \\
\hline & \multicolumn{2}{|c|}{ Meninos } & \multicolumn{2}{|c|}{ Meninas } & \multicolumn{2}{|c|}{ Total } & \multicolumn{2}{|c|}{ Meninos } & \multicolumn{2}{|c|}{ Meninas } & \multicolumn{2}{|c|}{ Total } \\
\hline & $\mathrm{N}$ & $\%$ & $\mathrm{~N}$ & $\%$ & $\mathrm{~N}$ & $\%$ & N & $\%$ & $\mathrm{~N}$ & $\%$ & $\mathrm{~N}$ & $\%$ \\
\hline A garota deve ser experiente & 5 & 10,2 & 6 & 8,8 & 11 & 9,4 & 4 & 9,8 & 2 & 3,7 & 6 & 6,3 \\
\hline $\begin{array}{l}0 \text { garoto sentirá mais que a } \\
\text { garota }\end{array}$ & 11 & 22,4 & 13 & 19,1 & 24 & 20,5 & 1 & 2,4 & 2 & 3,7 & 3 & 3,2 \\
\hline $\begin{array}{l}\text { Para o garoto é mais } \\
\text { importante }\end{array}$ & 2 & 4,1 & 1 & 1,5 & 3 & 2,6 & 4 & 9,8 & 1 & 1,9 & 5 & 5,3 \\
\hline $\begin{array}{l}\text { O garoto deve saber tudo sobre } \\
\text { o sexo }\end{array}$ & 1 & 2,0 & - & - & 1 & 0,9 & 3 & 7,3 & - & - & 3 & 3,2 \\
\hline $\begin{array}{l}0 \text { tamanho do pênis } \\
\text { influencia na relação }\end{array}$ & 6 & 12,2 & 4 & 5,9 & 10 & 8,5 & 1 & 2,4 & 1 & 1,9 & 2 & 2,1 \\
\hline NDA & 24 & 49,1 & 44 & 64,7 & 68 & 58,1 & 28 & 68,3 & 48 & 88,8 & 76 & 79,9 \\
\hline Total & 49 & 100,0 & 68 & 100,0 & 117 & 100,0 & 41 & 100,0 & 54 & 100,0 & 95 & 100,0 \\
\hline
\end{tabular}


ninos e meninas em ambos os momentos. Detectam-se mudanças estatisticamente notórias entre as respostas dos adolescentes quando comparados o pré e o pós-teste. Não houve distinção de gênero quanto a opinião sobre o prazer, pois no pré-teste $20,5 \%$ das respostas indicaram que no ato sexual o garoto sente mais prazer; já no pósteste, esse número caiu para $3,2 \%$.

Os adolescentes referem, tanto antes $(58,1 \%)$ e muito mais após as oficinas ( $79,9 \%)$, que nenhuma das alternativas sugeridas no questionário poderá influenciar no prazer sexual.

A questão sobre a importância de casar com alguém virgem também foi feita para os estudantes, mas os testes estatísticos revelaram que não houve diferenças de respostas entre meninos e meninas e entre os adolescentes de um modo geral no pré e pós-teste. Pode-se observar que, após as oficinas, a maioria $(40,0 \%)$ continua considerando importantea virgindade como critério de escoIha no casamento, 25,3\% dizem que não faz diferença e $23,1 \%$ não sabem responder.

Quanto ao fato de a garota andar com camisinha na bolsa, a maioria dos estudantes, tanto no pré como no pós-teste $(87,2 \%)$, apóia o fato da menina ter o preservativo constantemente.

\section{Discussão}

A população estudada, como se pode notar, concentra-sena faixa etária entre 14 e 16 anos deidade eo sexo feminino é predominante.

$\mathrm{Na}$ Tabela 2, pode-se verificar através dos testes estatísticos que tanto no pré-testecomo no póstestenão houve diferenças significativas entremeninos e meninas quanto ao conhecimento à respeito da localização do clitóris, área de prazer feminino, mas quando se comparou as respostas entreo pré-testee pós-teste, nota-se diferença considerável, mostrando que houve mudança de conhecimento entre os adolescentes de ambos os sexos, de $28,2 \%$ no pré-teste para $47,4 \%$ no pósteste. M esmo assim, o número de adolescentes informados sobre a localização do clitóris na mulher não chega à metade.

Nos estudos de Faustini et al. ${ }^{14} \mathrm{e}$ Paiva e Bles$\mathrm{sa}^{15}$, garotas conhecem pouco sobre o corpo erótico, aquilo que lhes dá prazer. Mas, neste estudo, pôde-se verificar queo conhecimento das meninas após as oficinas aumentou de 22,3\% para 53,7\%.

Ainda com relação ao corpo erótico, no que se refere à prática da masturbação, 16,8\% dos adolescentes deste estudo, após as oficinas de prevenção, ainda consideram um ato "pecaminoso".
Tal fato também é encontrado nos resultados das pesquisas de Paiva e Blessa e Souza et al., em que os estudantes continuam sentindo culpa pela prática da masturbação, principalmente entre as garotas ${ }^{15,16}$.

Tornou-se notório a importância que os adolescentes dão para o conhecimento do corpo, independente se for o seu ou o do sexo oposto, na busca de descobrir sua sexualidade.

Tal interesse deveser incentivado cada vez mais por parte dos educadores na busca de desenvolver nos adolescentes a preocupação com o autocuidado, visando promover neles a capacidade de decisão sobre práticas sexuais seguras.

Em contrapartida, ainda pôde-se observar, nos resultados deste estudo, que o conhecimento das meninas sobre o período fértil é pequeno no pré teste $(38,3 \%)$, mas no pós-teste aumentou para $66,7 \%$. Ainda assim, o conhecimento do corpo feminino continua baixo, principalmente entre as garotas.

O bserva-se, com estes resultados, características muito distintas de gênero. O utra característica peculiar entre os gêneros, neste estudo, é a iniciação sexual mais precoce entre os garotos em comparação às garotas. Tais resultados também são encontrados nas pesquisas de Paiva e Blessa, Souza et al., Jeolás e Ferrari, Trajman et al.,Oliveira, Bemfam e Taquete et al. ${ }^{15-20}$.

Segundo dados do M inistério da Saúde, em 1997, a média de idade da primeira relação sexual entre meninos era de 16 anos e, entre as meninas, de 19 anos. Em 2001, essa média baixou para $14 \mathrm{e}$ 15 anos, respectivamente ${ }^{21}$. Tal afirmação se confirma no estudo feito por Trajman et al. com 945 adolescentes entre 13 e 21 anos, no qual $59,0 \%$ deles iniciaram sexualmente com uma média de idade de 15 anos $^{18}$.

Ainda com relação à iniciação sexual, pesquisa realizada por Oliveira com 1.642 adolescentes de quinze a dezenove anos em treze escolas públicas do município de Londrina demonstrou que a mé dia da iniciação sexual foi de 14,2 anos para os meninos e 15, 1 para as meninas, dados estes também presentes nos resultados da pesquisa de $\mathrm{Her}$ cowitz 22,23 .

Um fator de risco para a iniciação sexual prematura é o fato da diminuição gradativa da idade média da entrada da puberdade, ou seja, o desenvolvimento fisiológico dos adolescentes está antecedendo o cognitivo e o emocional ${ }^{18,24}$.

Esta antecipação pode trazer como conseqüência a possibilidade de uma gravidez não planejada e a infecção com doenças sexualmente transmissíveis, pois soma-se ao fato de não haver um 
uso consistente de métodos contraceptivos e protetores das doenças.

Os métodos contraceptivos e de barreira mais conhecidos pelos adolescentes neste estudo também foram os do estudo de outros pesquisadores, justamente aqueles mais divulgados em campanhas governamentais e na mídia14,19,25.

Nota-se, neste estudo, que mesmo após a participação nas oficinas de prevenção, há desconhecimento dos métodos anticoncepcionais existentes, mais de $50 \%$. Desta forma, o adolescente torna-semais vulnerável ou desprotegido no momento em que um deles vier a ser utilizado nas relações sexuais.

Segundo Boruchovitch, osadolescentes são mal informados sobre métodos contraceptivos, mas a maioria deles pode identificar pelo menos um deles; geralmente, as meninas sabem mais sobre 0 uso de anticoncepcionais que os garotos ${ }^{24}$.

A mesma autora refere ainda que os adolescentestendem a apresentar atitudes negativas quanto ao uso de métodos de barreira, como o preservativo, referindo que os mesmos interferem no prazer sexual, retirando a naturalidade e espontaneidade do ato, e nem sempre ele está disponível no momento da atividade sexual.

Estudo de Jeolás e Ferrari mostrou alguns dos motivos do não uso do preservativo na relação sexual, um deles o esquecimento e outro que nem sempre a garota tem argumento de negociação para o uso do mesmo pelo parceiro ${ }^{17}$.

Quanto ao uso do preservativo, cabe salientar também que estudos de âmbito nacional e internacional apontam a uma relação entre a baixa escolaridade ea maior fecundidadee a maior escolaridade e a menor fecundidade devido à maior freqüência do uso do preservativo nas relações sexuais ${ }^{1,15,18,19,26 .}$.

Frente a esta realidade, pode-seafirmar o quanto énecessário investimentos na educação ena saúde, salientando que 0 adolescente não deve ficar fora da escola.

É importanteressaltar que o desconhecimento sobre a sexualidade e a saúde reprodutiva faz com que as adolescentes engravidem "sem querer"; muitas acabam engravidando por duvidar de sua fertilidade ou mesmo para provar sua heterossexualidade ${ }^{23}$.

Reafirma-se com essa informação o conceito de que 0 adolescente é visto, no âmbito das políticas públicas de saúde, como vulnerável, pelo fato de estar em fase de transformações biológicas, psicológicas e sociais e também por achar que os danos decorrentes do sexo desprotegido "não irão acontecer com eles" $33,5,7,20,27,28$.
Além da fragilidade do conhecimento sobre 0 corpo, sexualidadeefecundação, nesteestudo, preocupa 0 fato de, principalmente com relação às DST, $19,9 \%$ dos adolescentes, mesmo após terem participado das oficinas de prevenção, ainda afirmar não conhecer sequer um tipo de doença sexualmente transmissível.

Pesquisa de Trajman et al. mostra que os adolescentes têm concepções erradas sobre a transmissão das DST/aids, e muitas vezes eles se enganam com a aparência saudável do parceiro ${ }^{18}$.

Vários autores referem que os jovens possuem um sentimento de onipotência frente as DST/aids, tendo a convicção de que a infecção "nunca irá acontecer com eles"9,15,17,29.

Para confirmar a grande repercussão quea aids tem atingido nos últimos anos, em um estudo feito com 945 estudantes do ensino médio, no Rio de Janeiro, em 1999, descobriu-se que $100 \%$ deles já tinham ouvido falar sobre a aids ${ }^{18}$. Tal popularidade, segundo a fala dos próprios adolescentes em uma pesquisa feita por Toneli et al., édevido à grande preocupação das campanhas preventivas, veiculadas na mídia diariamente, o que faz com queo conhecimento sobre as demais DST fique prejudicado ${ }^{30}$.

Quanto ao prejuízo do conhecimento dos adolescentes sobre os meios de transmissão das outras DST, além da aids, pode-se observar neste estudo que, mesmo após a participação nas oficinas de prevenção sobre a temática, não houve mudança estatisticamentesignificativa.

Estudo de Lins et al. aponta que grande parte dos adolescentes considera erroneamente como meios de prevenir as DST a "utilização de locais higiênicos" e "não usar banheiros públicos" ${ }^{\text {. }}$.

A precariedade de conhecimento sobre as formas deprevenir as DST épreocupante epodeestar relaci onada diretamente à pouca ou à falta da qualidade no âmbito educacional das nossas escolas e outras instituições formadoras de opinião.

Segundo dados da Unaids, a metade das novas contaminações da aids no mundo, são de jovens entre 15 e 24 anos, e ocorrem de diversas formas, com destaque para as relações sexuais sem proteção e o uso compartilhado de drogas injetáveis ${ }^{26}$.

A prevenção da aids, principalmenteatravés do uso do preservativo, vem sendo maciçamente divulgada nas campanhas. No entanto, embora os adolescentes saibam que este método de barreira evita tanto a gravidez como as DST/aids, no Brasil ele ainda é pouco utilizado ${ }^{19,21,29}$.

Em se tratando de aids, todas as iniciativas no sentido de estimular a discussão e conscientização dos indivíduos a respeito de sua prevenção mere- 
cem ser apoiadas, mas é necessário avaliar a efetividade das mesmas, pois passado mais de vinte anos do advento da aids, esforços para o exercício de práticas seguras estão aquém das metas de controle da disseminação entre os adolescentes, fase em que se dá a iniciação sexual.

Segundo dados tanto das pesquisas nacionais como internacionais, os mais baixos índices deuso do preservativo nas relações sexuais continuam sendo entre 15 e 19 anos, principalmente entre as garotas e de baixa escolaridade, como referido anteriormente ${ }^{19,21,26}$.

Confirmando este comportamento de invulnerabilidade, 0 estudo de Jeolás e Ferrari mostrou que tais dados remetem mais uma vez a afirmar 0 quanto é difícil mudar valores e pensamentos cultural e socialmente preestabelecidos ${ }^{17}$.

É certo que este não foi o único objetivo das oficinas de prevenção para os adolescentes em estudo. A realização do trabalho em forma de oficinas a partir da aprendizagem compartilhada, na qual os coordenadores não ensinam o "certo e o errado", mas facilitam o debate entre os pares a partir de dúvidas, opiniões e valores, remete os participantes à possibilidade de ampliar os seus próprios recursos de autoproteção.

Deste modo, torna-se evidente que trabalhar a mudança de comportamento visando à sexualidade "saudável" significa uma árdua e demorada tarefa, necessitando de interven ções freqüentes, objetivando a reconstrução de atitudes responsáveis.

Isto reforça o quanto é necessário rever as práticas educativas a serem realizadas com adolescentes e a freqüência com que devem ser feitas; além disto, se torna imprescindível a participação dos educadores e familiares neste processo, pois este grupo etário ainda tem buscado com amigos informações, nem sempre são corretas, tal fato por característica deste grupo etário mas também pela ausência ou até omissão tanto dos setores de educação e saúde como da família.

Isto revela que tanto o setor da saúde como o da educação não estão dando conta da integralidade à saúde dos adolescentes.

Enquanto não há uma sistemática intersetorialidade entre estes dois setores, trabalhos realizados em escolas continuam mostrando a fragilidade de conhecimento e comportamento dos jovens. É o queaponta o estudo deAntunes et al.com 394 estudantes de 18 à 25 anos, de escolas públicas noturnas de São Paulo, que participaram de "oficinas de sexo mais seguro". Os rapazes tinham como fala inicial "saber tudo sobre sexo"e "poder tudo", mas depois de seis meses da realização da interven ção, reconheceram não serem tão "sabidos" assim²9.
Neste estudo de Toneli et al., mesmo que não haja diferenças significativas de conhecimento entre os gêneros e as formas de prazer, os adolescentes demonstram a preocupação em garantir o próprio prazer e satisfação do parceiro, denotando uma flexibilidade no comportamento de onipotência eabertura para discutir as relações para práticas de sexo seguro ${ }^{30}$.

A pesar da prática do sexo estar sendo cada vez mais difundida em todas as camadas sociais, através do incentivo de sua liberação, muitas garotas ainda se preocupam com a virgindade; já para os garotos, o sexo ésinal de masculinidade, para não ser confundido com "viados" 15 .

As questões relacionadas ao gênero evidenciam o processo de construção social, histórica e cultural das representações do masculino efeminino na prática social, expressam diferenças significativas de como 0 adolescenteviveepensa ${ }^{17}$. Neste sentido, as imbricadas relações de gênero fazem das meninas um grupo socialmente mais vulnerável dos que os meninos, pois ainda sentem-se incapazes de negociar o uso do preservativo nas práticas sexuais, principalmente por influência do namorado, por ter confiança no parceiro, impulso, pressa e imprevisibilidade do ato sexual, restando pouca alternativa para elas se prevenirem contra a gravidez, DST e aids $3,15,17,29$.

\section{Conclusões}

A realização de oficinasjunto aos al unos da $8^{a}$ série do ensino fundamental de uma escola pública da região sul do município de Londrina, Paraná, permite concluir que o conhecimento desses alunos melhorou em vários aspectos relacionados à sexualidade, gravidez eDST.

O bservou-se que os adolescentes preocupamse em aprender mais sobre o seu corpo e o corpo do parceiro, principalmente no que diz respeito aos órgãos envolvendo sua sexualidade.

Notou-se que um número maior demeninosjá tiveram relações sexuais; no entanto, têm menor conhecimento sobre o período que a garota pode engravidar. De um modo geral, os adolescentes pouco conhecem sobre os diferentes métodos contraceptivos, tornando-se vulneráveis devido à falta de opção para evitar uma gravidez não planejada.

Não houve acréscimo de conhecimento sobre os métodos de transmissão das DST. A aids continua sendo a DST mais citada, deixando assim evidente a dificuldade de se mudar conceitos preestabelecidos, pela mídia e pela população deum modo geral, que ainda teme contrair o HIV, mas conti- 
nua sem saber realmente as verdadeiras formas de contágio das outras DST existentes muito antes do surgimento da aids.

Apesar da grande liberação sexual evidenciada nas últimas décadas, grande parte dos adolescentes ainda importa-se em procurar um parceiro virgem para casar, acha importante a menina andar com camisinha na bolsa e demonstrou que não considera corretas algumas afirmações distorcidas a respeito do prazer sexual.

Considera-sequea escola constitui espaço adequado para a implementação de programas educativos,levando-seem conta a participação dos pares (amigos), professores e familiares nessas ações.

A metodologia através de oficinas parece ter ampliado o conhecimento dos adolescentes mes- mo por ter sido realizada em apenas dois encontros. Portanto, pode-se vislumbrar que este método em forma de oficina favorece espaço de discussão, de troca de experiências pessoais e do grupo, partindo da realidade para a reflexão eo debate de suas próprias práticas. Com isso, pretende-se formar adolescentes multiplicadores do conhecimento. Para isso, contudo, há necessidade da continuidade das ações de prevenção desenvolvidas nesta pesquisa, envolvendo assim as instituições de ensino também.

Os resultados deste trabal ho são difíceis de serem avaliados a curto prazo; no entanto, almejase contribuir com a melhora do nível de conhecimento desses sujeitos, possibilitando assim a adesão de práticas sexuais seguras, evitando-se a gravidez não planejada, assim como as DST/aids.

\section{Colaboradores}

EAIC participou do projeto, revisão bibliográfica, análise e discussão dos resultados e redação final; RAPF é autora, coordenadora do projeto e orientadora desde a concepção até a redação final da pesquisa.

\section{Agradecimentos}

Em especial a Luiz Fabrício M elo do Departamento de Estatística, Centro de Ciências Exatas, Universidade Estadual de Londrina, pela paciência e dedicação no trabalho com o banco de dados e análise dos resultados; Dra. Elma Mathias Dessunti, docente do Departamento de Enfermagem da Universidade Estadual de Londrina, também colaborou no projeto, junto aos acadêmicos, na construção do banco de dados. 


\section{Referências}

1. Lunardelli JL. Anticoncepção na adolescência. Pediatria M oderna 2002; 38(8):381-387.

2. Organización Mundial de La Salud. La salud de los jóvenes: un reto y una esperanza. Genebra, 1995.

3. Saito MI. Adolescência, sexualidade e educação sexual. Pediatria Moderna 2001; 27:3-6.

4. Chauí M. Repressão sexual: essa nossa (des) conhecida. São Paulo: Brasiliense; 1987.

5. Calazans G. Os jovens falam sobre sua sexualidade e saúde reprodutiva: elementos para reflexão. In: Abramo HH, Branco PPM, organizadores. Retratos da juventude brasileira: Análises de uma pesquisa nacional. São Paulo: Editora Cidadania; 2005. p. 215-241.

6. Gir E, Nogueira MS, Pelá NTR. Sexualidade humana na formação do enfermeiro. Rev. Latino-Am. Enfermagem 2000; 8(2):33-40.

7. Bruns MAT, Grassi M FC, França C. Educação sexual numa visão mais abrangente. Rev. Bras. Sexualidade Humana 1995; 6(1):60-66.

8. Lins LCS, Pereira EM DR, Lira IV. Como anda a educação sexual dos jovens. Rev Bras Enferm 1988; 41(2):121-131.

9. Cano MAT, Ferriani M GC. Sexualidade na adolescência: um estudo bibliográfico. Rev. Latino-Am. Enfermagem 2000; 8(2):18-24.

10. Londrina. Secretaria M unicipal de Planejamento. Síntese do perfil do município de Londrina 2003: baseado nos dados de 2002. Londrina, 2003 [acessado 2005 fev 10]. Disponível em: http://www.londrina.pr.gov. br/perfil2003.htm

11. Brasil. M inistério da Saúde. Secretaria de Assistência à Saúde. M anual do M ultiplicador - Prevenção às DST/ aids. Brasília: M inistério da Saúde; 1996.

12. Dean AG. Epi Info, version 3.3.2. A word processing, database and statistics program for epidemiology on microcomputers. Atlanta: Center for Disease Control and Prevention; 2005.

13. Brasil. M inistério da Saúde. Conselho Nacional de Saúde. Diretrizes e normas reguladoras de pesquisa envolvendo seres humanos. Brasília: Ministério da Saúde; 1997.

14. Faustini DMT, Novo NF, Cury M CFS, Juliano Y. Programa de orientação desenvolvido com adolescentes em centro de saúde: conhecimentos adquiridos sobre os temas abordados por uma equipe multidisciplinar. Cien Saude Colet 2003; 8(3):783-790.

15. Paiva V, Peres C, Blessa C. Jovens e adolescentes em tempos de aids: reflexões sobre uma década de trabalho de prevenção. Psicol. USP 2002; 13(1).

16. Souza RP, Oliveira JS, Wagner M B, Vinciprova AR. Estudo comparativo sobre o comportamento sexual da juventude secundarista e universitária de Porto Alegre, Brasil. Rev. Latino-Am. Enfermagem 1997; 1(1):20-30.

17. Jeolás LS, Ferrari RAP. Oficinas de prevenção em um serviço de saúde para adolescentes: espaço de reflexão e de conhecimento compartilhado. Cien Saude Colet 2003; 8(2):611-620.
18. Trajman A, Belo MT, Teixeira EG, Dantas VCS, Salomão FM, Cunha AJ, Ledo A. Knowledge about STD/ AIDS and sexual behavior among high school students in Rio de Janeiro, Brazil. Cad Saude Publica 2003; 19(1):127-133.

19. Bemfam. Sociedade Civil Bem-Estar Familiar no Brasil. Adolescentes, jovens e a pesquisa nacional sobre demografia e saúde: um estudo sobre fecundidade, comportamento sexual e saúde reprodutiva. Rio de Janeiro: CDC/UNICEF; 1999.

20. Taquette SR, De Vilhena M M, De Paula M C. Doenças sexualmente transmissíveis na adolescência: estudo de fatores de risco. Rev. Soc. Bras. Med. Trop. 2004; 37(3):210-214.

21. Brasil. Secretaria de Políticas de Saúde. Programa Nacional de DST e aids: Dados e pesquisas em DST e aids. 2003. [acessado 2005 nov 09]. Disponível em: http://www.aids.gov.br/final/dados/dst.htm

22. Oliveira RLC. Estudo sobre o conhecimento de doenças sexualmente transmissíveis e comportamento sexual de adolescentes do ensino médio de escolas públicas de Londrina, PR [dissertação]. Londrina (PR): Departamento de Saúde Coletiva, U niversidade Estadual de Londrina; 2002.

23. Hercowitz A.Gravidez na adolescência. Pediatria M oderna 2002; 38(3):392-395.

24. Boruchovitch $E$. Fatores associados a não-utilização de anticoncepcionais na adolescência. Rev. Saúde Pública 1992; 26(6):437-443.

25. Guimarães AM ADN, Viera MJ, Palmeira JA. Informações dos adolescentes sobre métodos anticoncepcionais. Rev. Latino-Am. Enfermagem 2003; 11(3):293-298.

26. Unaids. Focus-HIV and young people: the threat for today's youth. In: Report on the global AIDS epidemic 2004. [acessado 2005 out 29]. Disponível em: http://www.unaids.org

27. M orais VO, M oura M VQ, Costa COM, Patel BN. Doenças sexualmente transmissíveis, aids e uso/abuso de substâncias psicoativas na adolescência. J. Pediatr. 2001; 77(2):190-202.

28. Taquette SR, Andrade RB, Vilhena MM, De Paula MC. A relação entre as características sociais e comportamentais da adolescente e as doenças sexualmente transmissíveis. Rev. Assoc. M ed. Bras. 2005; 51(3):148-152.

29. Antunes $A C$, Peres $C P$, Paiva $V$, Stall $R$, Hearst $N$. Diferenças na prevenção da aids entre homens e mulheres jovens de escolas públicas em São Paulo, SP. Rev. Saúde Pública 2002; 36(4):88-95.

30. Toneli MJF, M endes D, Vavassori M B, Guedes T, Finkler I. Concepções e práticas de adolescentes do sexo masculino sobre sexualidade. PsicoU SF 2003; 8(2): 203-211.

Artigo apresentado em 06/07/2006

Aprovado em 25/07/2006

Versão final apresentada em 09/12/2008 